\title{
Article
}

\section{Data Co-Operatives through Data Sovereignty}

\author{
Igor Calzada $1,2,3$ (1)
}

check for

updates

Citation: Calzada, I. Data

Co-Operatives through Data

Sovereignty. Smart Cities 2021, 4 ,

1158-1172. https://doi.org/10.3390/

smartcities4030062

Academic Editor: Pierluigi Siano

Received: 15 August 2021

Accepted: 3 September 2021

Published: 5 September 2021

Publisher's Note: MDPI stays neutral with regard to jurisdictional claims in published maps and institutional affiliations.

Copyright: (C) 2021 by the author. Licensee MDPI, Basel, Switzerland. This article is an open access article distributed under the terms and conditions of the Creative Commons Attribution (CC BY) license (https:// creativecommons.org/licenses/by/ $4.0 /)$.
1 Civil Society Centre ESRC, School of Social Sciences, Cardiff University, Wales Institute of Social and Economic Research and Data (WISERD), 38 Park Place, Cathays Park, Cardiff-Caerdydd CF10 3BB, UK; calzadai@cardiff.ac.uk; Tel.: +44-(0)-7887661925

2 Urban Transformations ESRC, COMPAS, University of Oxford, 58 Banbury Road, Oxford OX2 6QS, UK

3 People-Centered Smart Cities Flagship Programme, Digital Transformation in Urban Areas, UN-Habitat, P.O. Box. 30030, Nairobi GPO 00100, Kenya

\begin{abstract}
Against the widespread assumption that data are the oil of the 21st century, this article offers an alternative conceptual framework, interpretation, and pathway around data and smart city nexus to subvert surveillance capitalism in light of emerging and further promising practical cases. This article illustrates an open debate in data governance and the data justice field related to current trends and challenges in smart cities, resulting in a new approach advocated for and recently coined by the UN-Habitat programme 'People-Centred Smart Cities'. Particularly, this feature article sheds light on two intertwined notions that articulate the technopolitical dimension of the 'People-Centred Smart Cities' approach: data co-operatives and data sovereignty. Data cooperatives are emerging as a way to share and own data through peer-to-peer (p2p) repositories and data sovereignty is being claimed as a digital right for communities/citizens. Consequently, this feature article aims to open up new research avenues around 'People-Centred Smart Cities' approach: First, it elucidates how data co-operatives through data sovereignty could be articulated as long as co-developed with communities connected to the long history and analysis of the various forms of co-operatives (technopolitical dimension). Second, it prospectively anticipates the city-regional dimension encompassing data colonialism and data devolution.
\end{abstract}

Keywords: data co-operatives; data sovereignty; data colonialism; data devolution; smart cities; people-centred smart cities; platform co-operatives; COVID-19; blockchain; foundational economy

\section{Introduction: Data Are Not the Oil of the Twenty-First Century}

There is a widespread assumption that data are the oil of the twenty-first century [1]. This phrase is the cliche du jour of the tech-smart city industry, which has turned out to be a viral idea shared by marketers, tech companies, governments, regulators, and mainstream media commentators [2-4]. This metaphor portrays public data as passive and untapped resources that have value only when they are extracted [5]. As such, this framing completely removes the individual agency created. Data are created in real time, as individuals click and swipe around the internet [6]. Consequently, what is absent in this mainstream metaphor is essentially that data sharing should be based on trust and social capital that emerged in communities from peer-to-peer interactions. This metaphor, therefore, might work in an economic sense, but it fails to describe what data are as material assets: Data are not oil; they are people. This contrasts with the imperative that data should inevitably be monetised as a one-size-fits-all, business-as-usual solution. By contrast, according to Sadowski et al. [7] (p. 169), 'everyone should decide how their digital data are used-not just tech companies'.

Hence, stemming from the counterinterpretation of the metaphor 'oil equals data', this article suggests an alternative pathway in light of several emerging and promising practical cases to revert surveillance capitalism in smart cities [8]. It illustrates an open debate in data governance and data justice field related to current trends and challenges in smart cities. 
Particularly, this feature article sheds light on two intertwined technopolitical notions that are paving the way towards the new UN-Habitat approach called 'People-Centred Smart Cities': data co-operatives and data sovereignty.

It must be acknowledged that these concepts may have been separately already emerging in current discussions about smart cities. Nonetheless, it is equally true that these current debates on trends and challenges about the so-called technocratic smart city approach still need people-centred or citizen-centric overarching, transitional, and experimental frameworks to further democratise citizenship and subvert the path-dependency of surveillance capitalism and sensory power in post-COVID-19 contemporary societies [9]. Smart infrastructures have propelled an industry of smart technology producers to pursue a technological solutionism that often dismisses the multi-layered implications of the platform economy and society, and more importantly, the side effects of datafication over citizens amid the pandemic.

Consequently, this article explores the following research question: How can the potential emerging alternative around data co-operatives be described in parallel with data sovereignty in the post-COVID-19 era, given that both technopolitical notions are intertwined and also explicitly presented as key principles of the new 'People-Centred Smart Cities' approach, coined by UN-Habitat to subvert the negative side-effects on social exclusion and the digital and data divide stemming from existing and hegemonic surveillance capitalism and sensory power [8,9]. The article introduces these two intertwined technopolitical notions alongside the new 'People-Centred Smart Cities' approach as a way to open up new research avenues related to the prevailing nexus between smart cities and data [10].

By describing these intertwined relationships between data co-operatives [11], data sovereignty [12], and the 'People-Centred Smart Cities' approach [13], this article-as shown in Figure 1-addresses several technopolitical discussions by providing a systematic angle and offering a thorough literature review about each of these notions to prove that outlined statements remain valid and relevant [14]. At the end of the article, the cityregional dimension is prospectively anticipated as the next step to be considered in the future development of the 'People-Centred Smart Cities' approach [15]. The article thus aims to offer a framework to describe the present (technopolitical dimension) and anticipate the potential prospective advancements (city-regional dimension) around 'People-Centred Smart Cities' [16].

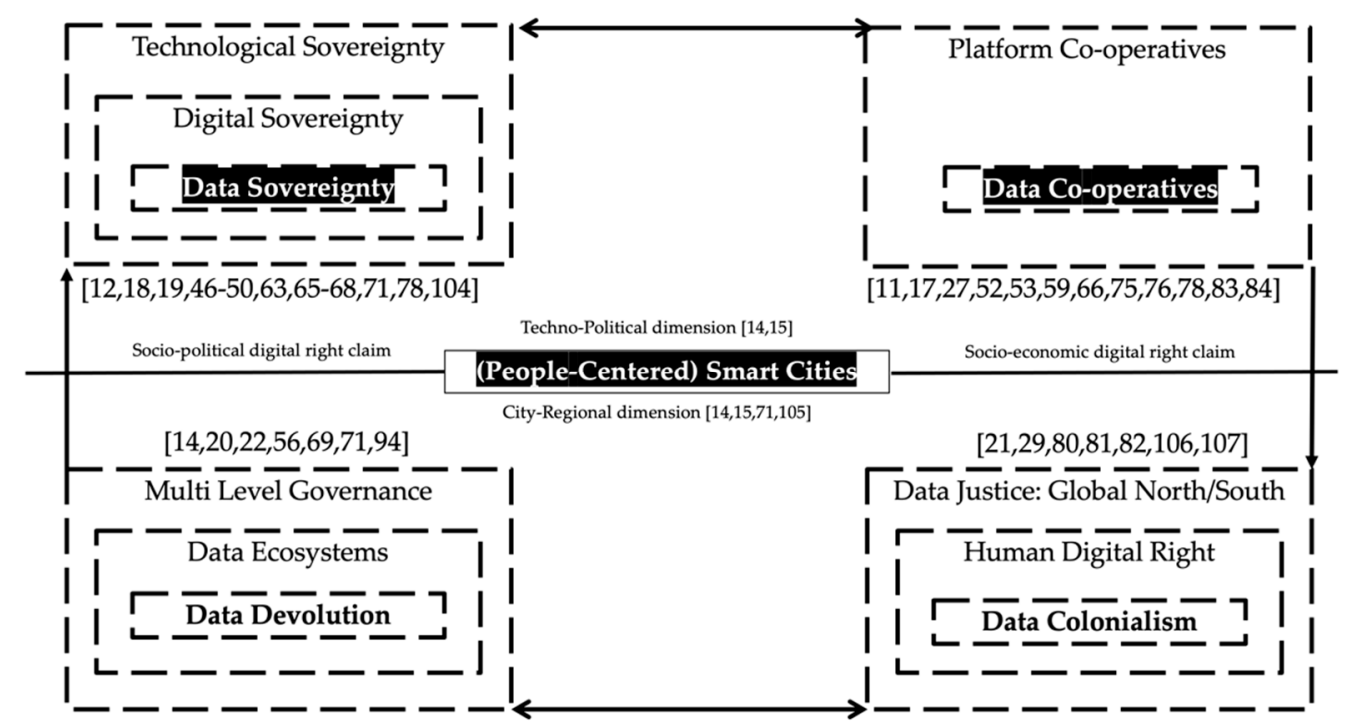

Figure 1. Framework, structure, and literature review: technopolitical dimension of the 'PeopleCentred Smart Cities' consisting of data co-operatives through data sovereignty. 
The article is structured as follows: (i) the Introduction Section presented the rationale and research question; (ii) Section 2 will introduce a discussion around data cooperatives being understood as $\mathrm{p} 2 \mathrm{p}$ data-sharing and ownership organisational forms [17]; (iii) Section 3 will describe the main challenges with implementing data sovereignty in a wide range of city-regional contexts that could already claim to have a plethora of digital rights for communities and citizens [18,19]; (iv) Section 4, consequently, blends the data co-operatives (second section) and data sovereignty (third section) in relation to the new formulation coined by UN-Habitat in 2018 as 'People-Centred Smart Cities' by providing a transitional framework to subvert surveillance capitalism; (v) lastly, Section 5 elucidates its main contribution, the novelty of its standpoint, its existing limitations, its inspirational intention, and potential future research avenues to elaborate on the city-regional dimension of the 'People-Centred Smart Cities' approach: data devolution [20] and data colonialism [21].

\section{Data Co-Operatives: Socioeconomic Digital Right Claim through P2P Data Sharing and Ownership}

Big data-extremely large data sets that may be analysed computationally-originated with the increasingly advanced data collection capabilities of the internet, social networks, the Internet of Things (IoT), artificial intelligence (AI), and sensors [22]. However, this AI-driven algorithmic phenomenon has led to new consequences, such as hyper targeting through data analytics, facial recognition, and individual profiling, received by many with both helplessness and threat, resulting in not-so-desirable outcomes, such as massive manipulation and control via the surveillance capitalism push in the US and the Social Credit Systems in China [23].

In contrast, these societal concerns raised a debate in Europe that crystalised into the General Data Protection Regulation (GDPR) coming into force since May 2018 [24], becoming thereafter a fully fledged inspiration for several data regulations worldwide, including the California Consumer Privacy Act (CCPA) [25]. Yet, while the discussion around data governance has spurred fruitful debates [26], we must confess more nuanced and humble cases, grounded in practice, are required to pave the way. At present, most alternative initiatives stemming from platform co-operatives [27] are based on services provided by Amazon Web Services (AWS), which has revealed the insurmountable hindrances related to how hard is to bypass data extractivism [28-30].

Criticism of platforms that do not adhere to democratic principles has led to the emergence of an alternative proposition, known as platform cooperativism: worker-owned cooperatives based on open-source technologies, which respect ethical working conditions and redistribute to the users the value they have created [31,32].

Amidst post-pandemic uncertainties, COVID-19, and now its Delta variant, have hit pandemic-stricken citizens dramatically worldwide, creating a general risk-driven environment encompassing a wide array of economic vulnerabilities and also exposing them to pervasive digital risks, such as bio-surveillance, misinformation, and e-democracy algorithmic threats. It has become clear how deeply data practices are connected to democracy.

Recently, in this similar vein, Ada Lovelace Institute found a 'data divide' of inequalities in access, knowledge, and awareness of digital health technologies used in the pandemic, such as symptom-tracking apps, contact-tracing apps, and consumer-facing mental and physical health apps [33]. The long-researched 'digital divide' risks transforming into the 'data divide', as data-driven technologies developed in response to the coronavirus pandemic, such as vaccine passports, benefit, represent, and respond to the needs of some people and some groups more than others [34]. Hence, a much more inclusive approach to developing data and data-driven systems is required.

Moreover, we are now witnessing the side effects of an uneven global vaccination and its aftermath [35]. First, the paradox of vaccines passports (supposedly a tool meant to unite the world after lockdown) could now instead end up balkanising it into closed systems where only certain apps are accepted, only certain vaccine brands are welcome, only some documentation is accessible to cross any border and enter a country [36]. Second, 
the global race for doses has also affected which countries receive which vaccines, resulting in extreme protectionism also known as 'vaccine nationalism' [37,38]. Additionally, third, despite the fact that biometric technologies from facial recognition to digital fingerprinting have proliferated through society in recent years, the benefits they offer are clearly counterbalanced by numerous ethical and societal concerns [39].

The quantity of data, and the resulting power, held by a small number of players (so-called GAFAM: Google, Amazon, Facebook, Apple, and Microsoft) has already created a counterreaction in the European continent [40]. The European Strategy for Data [41] and the Data Governance Act [42] attempt to provide an alternative driven by data sovereignty (whatever it might mean in both European Union as well as worldwide, and particularly in the Global South regarding data colonialism) [21,43]. Recent years have seen an emergence of this notion to claim data ownership in debates on the development, implementation, and adjustment of new data-driven technologies and their infrastructures. Despite its unclear territorial and technopolitical jurisdiction, data sovereignty is exemplified through national data sovereignty in cloud computing, indigenous data sovereignty [44-46], and (more intensively now) patient data sovereignty claims. At the end of the day, the concentration of power around data has been counter reacted by claims stemming from national and political interests, indigenous population's digital rights, and users-consumers-workerscitizens' digital rights [47-50].

In the European continent, data sovereignty has adopted a legal form of data altruism and donation, meaning that individuals can choose the way their data can be stored [51]. However, it remains to be seen how this data sovereignty enables citizen organisations helping us move from the current paradigm of individuals giving up data to large big tech entities to a system based on collective data rights and accountability, complete with legal standards and fiduciary representation. Therefore, this article argues that these co-operative forms known as 'data co-operatives' are a subcategory of the widespread phenomenon called 'platform co-operatives' [17,31,32].

Data co-operatives are member-owned data management storages (e.g., credit unions) with fiduciary obligations to members, where all data usage is for the benefit of members and done only with their consent; it is driven by privacy preservation. Data co-operatives focus on data interactions among citizens and not essentially on the core social value behind them [52,53].

Hence, arguably, the current pandemic and democracy are pervasively related to data governance issues, exposing citizens' vulnerability in a potential surveillance state [54]. However, how can job quality (or worker power) be ensured for all platform workers while also creating further democratic socioeconomic platformised alternatives to revert algorithmic and data politics (data oligopolies) extractivist, business-as-usual hegemonic paradigm [55]? At this stage, consequently, we may also ask whether it is possible to alter existing data governance extractivist models to incentivise the emergence of platform co-operatives [56,57] and data co-operatives [58,59], thereby protecting pandemic citizens' labour and digital rights [60].

Never before has the crucial role that co-operative organisational forms-currently reignited and reinforced through updated reformist paradigms such as the foundational economy paradigm - play in sustaining the social fabric of communities, societies, and economies become so visible to a broad public [31], nor has the need for such organisational forms ever been more evident. Worldwide, in the post-COVID-19 era, neighbourhoods, associations, co-operatives, and civic groups have self-organised to help guarantee access to life-saving resources such as food, health services, IT equipment, clothes, shelter, and psychological support to those in need $[61,62]$. One such case is the data co-operatives that are being increasingly studied broadly in the academic literature and policy implementations as a base to provide solid research; for example, the recent article published in the journal Sustainability [17] by the author of this article shows a deep examination of more than 159 platform and data co-operatives. The present article stems from that empirical examination by offering a novel framework to connect the potential formation of data 
co-operatives with the necessary fertile sociopolitical ecosystem enabled through a certain degree of data sovereignty for citizens and communities [63].

At present, there are several data co-operative such as Salus, Driver's Seat, MyData, LBRY, dOrg.tech, and Polypoly, which are so far intensively implemented.

Salus Coop is a non-profit data co-operative for health research (referring to health data and lifestyle-related data more broadly, such as data that capture the number of steps a person takes in a day), founded in Barcelona in September 2017. Salus aims to create a citizen-driven collaborative governance model and management of health data. It legitimises citizens' rights to control their health records while facilitating data sharing to accelerate public research innovation in healthcare.

Driver's Seat is a data co-operative founded in 2019 in Milwaukee, Wisconsin. Driver's Seat is a driver-owned co-operative that empowers ride-hail drivers and on-demand delivery workers to use shared data ownership to make the gig economy work better for themselves and the communities they serve. Driver's Seat has developed an app to collect data from on-demand drivers to (i) return it to drivers in the form of actionable insights to optimise their earnings and (ii) sell the collected data to local and state government to use in planning and design, policy creation, and enforcement.

MyData is a health data co-operative started in 2015. MyData.coop enables citizens to securely store, manage, and control access to their personal data by helping them to establish and own national/regional non-for-profit MyData co-operatives. MyData cooperatives act as the fiduciaries for their members' data. MyData offers a platform on which user members can securely store copies of their medical records, genomes, and mHealth data. Members might decide to give their physicians access to all personal data through the platform. In contrast, a not-for-profit cancer research institute could be given access to only medical and dietary information. Members could deny access to a for-profit drug company. Members' revenues from the sale of data are donated to public research.

LBRY states 'we think users should own their content (and their privacy) instead of handing it over to a corporate giant and their advertising buddies. If you think we are paranoid, there are dozens of examples of companies abusing users and acting against their interests. It is not paranoia if they are actually out to get you'.

dOrg.tech currently transitioning to a data co-operative, is a full-stack development collective that works with industry-leading projects in Web3 by using a decentralised manner by builders worldwide through smart contracts, blockchain, and Ethereum.

Polypoly is a data co-operative that ensures that personal data no longer leave a device, whether mobile phone, computer, or web-enabled toaster. PolyPod, the member of the co-operative, has a private server that stores his/her data, and they are controlled by him/her.

Moreover, stemming from the author's previous empirical research on data cooperatives [17], and specifically as empirical evidence of this article, below in Table 1, is the full and updated list of 31 data co-operatives identified through the data set by the Platform Cooperativism Consortium [64]. 
Table 1. Data co-operatives: empirical evidence.

\begin{tabular}{|c|c|c|c|}
\hline \multicolumn{2}{|r|}{ Data Co-Operative } & \multirow{2}{*}{$\begin{array}{l}\text { www } \\
\text { Intensively Impl }\end{array}$} & \multirow[t]{2}{*}{ Sector/Activity } \\
\hline & & & \\
\hline 1. & Salus. Coop & www.saluscoop.org & Health \\
\hline 2. & Driver Seat & www.driversseat.co & Transport \\
\hline 3. & MyData & www.mydata.org & Data management \\
\hline 4. & LBRY & www.lbry.com & Blockchain-based file sharing and payment network \\
\hline 5. & dOrg.tech & www.dorg.tech & Full-stack development collective \\
\hline 6. & Polypoly & www.polypoly.org & Personal data storage \\
\hline \multicolumn{4}{|c|}{ Being Developed/Prototyped } \\
\hline 7. & Boniffi (former CULedger) & www.boniffi.com & $\begin{array}{l}\text { P2P services network of verifiable exchange for } \\
\text { financial cooperatives }\end{array}$ \\
\hline 8. & Cozy & www.cozy.io & Personal data storage \\
\hline 9. & Mydex & www.mydex.org & Personal data storage \\
\hline 10. & OpenAQ & www.openaq.org & $\begin{array}{l}\text { Non-profit organisation empowering communities to clean } \\
\text { their air by using open air quality data }\end{array}$ \\
\hline 11. & OpenHumans & www.openhumans.org & P2P knowledge production \\
\hline 12. & Decode & www.decodeproject.eu & Tools to keep personal data private \\
\hline 13. & Decidim & www.decidim.org & $\begin{array}{l}\text { Free open-source participatory democracy for cities } \\
\text { and organisations }\end{array}$ \\
\hline 14. & MetaDecidim & www.meta.decidim.org & Participatory process \\
\hline 15. & OpenDataManchester & www.opendatamanchester.org.uk & $\begin{array}{l}\text { It is a not-for-profit formed a diverse group of open data } \\
\text { advocates in } 2010 \text { that supports organisations to release data } \\
\text { and helps people use it }\end{array}$ \\
\hline 16. & TheGoodData & www.thegooddata.org & This co-operative is now on hold \\
\hline 17. & Health Bank & www.healthbank.coop & App with personal health history \\
\hline 18. & Ubiquitous Commons & www.ubiquitouscommons.org & Commons-driven tools \\
\hline 19. & Data Commons Cooperative & www.datacommons.coop & Data co-operative running community-driven projects \\
\hline 20. & Waze & www.waze.com & Transport \\
\hline 21. & Bank of the Commons & www.bankofthecommons.coop & $\begin{array}{l}\text { Cooperative banking service whose aim is to support } \\
\text { alternative economy projects and social movements on both a } \\
\text { global and a local level }\end{array}$ \\
\hline 22. & Market. Fair & www.market.fair.coop & FairCoop's online market. \\
\hline 23. & Find. Coop & www.find.coop & Directory of alternative economic projects in North America \\
\hline 24. & Gisc.coop & www.gisc.coop & $\begin{array}{l}\text { Farmer owned national data cooperative headquartered in } \\
\text { Lubbock, TX. }\end{array}$ \\
\hline 25. & Moedaseeds & www.moedaseeds.com & $\begin{array}{l}\text { Blockchain-based digital banking, payments, and } \\
\text { microcredit services }\end{array}$ \\
\hline 26. & OpenCreditNetwork & www.opencredit.network & Cooperative banking \\
\hline 27. & Patient Critical Co-op & www.patientcritical.com & $\begin{array}{l}\text { Canada's only patient-owned and steered healthcare } \\
\text { advocacy and education co-operative }\end{array}$ \\
\hline 28. & Privacy Co-op & www.privacyco-op.com & Data justice cooperative \\
\hline 29. & RChain & www.rchain.coop & Blockchain platform and key social coordination technologies \\
\hline 30. & RobinHoodCoop & www.robinhoodcoop.org & Generic coop \\
\hline 31. & SomConnexio & www.somconnexio.coop & Cooperative phone operator \\
\hline
\end{tabular}


Notably, the aim of this article is not to provide empirical data or any kind of experiment on this topic. Instead, this feature article aims to open up new research avenues by elucidating how data co-operatives (as a subcategory of platform co-operatives) [17] require a certain degree of data sovereignty as a technopolitical strategy to allow for being co-developed with local and regional communities. These communities show a long history and intrinsic co-operative traditions as a natural way to feed the new approach coined by UN-Habitat called 'People-Centred Smart Cities'.

\section{Data Sovereignty: Sociopolitical Digital Right Claim for Communities and Citizens}

According to Pentland and Hardjono, with 100 million members of credit unions, the opportunity for community organisations to leverage community-owned data is massive [52]. Nonetheless, data sovereignty has been used so far for advocacy, and it seems now more a claim than something that can be easily achieved in practice [65]. In fact, data flows are complicated and not easy to be tracked, as we are witnessing in the aftermath of COVID-19. Furthermore, the legal rights associated with data flows depict a complex set of boundaries when it comes to ownership of data. While there exists a remarkable degree of harmonisation and coherence around data protection's core principles in key international and regional agreements and guidelines, there are diverging implementation practices around data flows. In addition, Hardjono and Pentland advocate how financialising personal data, data co-operatives might emerge at the community level [53]. However, this is rather unlikely without any means of controlling data flows and ensuring data sovereignty for members of specific local communities [66].

Data sovereignty involves, or can be identified with, the control of data flows with national jurisdiction [67]. Nevertheless, as these studies themselves indicate, further systematic analyses are needed for questioning the generalisability of data sovereignty [68]. As such, data sovereignty presents a broad variety of themes, including the authority of national governments over data stored in domestic or foreign clouds, as well as indigenous-, community-, or nation-building groups, and patient data sovereignty over health data. The linkage between data co-operatives and data sovereignty lies in the fact that data co-operatives may rely considerably on the right and the degree of effectivity of this sovereignty in relation to their citizens' own data. Aside from this path dependency, the effectiveness of data sovereignty requires the willingness of co-operatives' members to donate their data altruistically. Consequently, this article acknowledges that the 'PeopleCentred Smart Cities' approach, led by UN-Habitat and inspired by principles of the foundational economy [31], may need to advocate for implementations of data ecosystems worldwide [20,69] —at the city-regional level through multi-level governance policy frameworks and data devolution schemes- to allow certain degrees of autonomy or data sovereignty in communities facilitating the creation of data co-operatives.

Hence, data co-operatives being a voluntary collaborative pooling by individuals of the personal data for the benefit of the membership of the group or community, present several shortcomings as well. Some advocates may see only the data pooling process as a purely technical process, whereas it is clearly a social-communitarian process based on trust and related to social capital. As Loukissas argued, all data ultimately are local; thus, the territorial and local dimensions of this discussion cannot be overlooked. It is key that the ability to balance the world's data economy inevitably depends on the fair interplay among stakeholders [70]. Consequently, it is clear that citizens and workers by themselves have no direct representation, yet consumers who were able to control their data would be a force to be acknowledged when their data would be localised/territorialised in certain data ecosystems [71].

Communities using their own data require decentralised and federated data ecosystems arranged by sectors (health-related data, environmental data, transport and mobility data, energy, consumption data, etc.) being clearly located in specific places, allowing to interoperation with each other, unless members of the community decide not to do so. This would mean owning data and being sovereign about their own data members produce. 
This article suggests that data should be co-operativised among members (citizens or workers) of communities. For co-operativising data, this article considers that localising data require at the same time trans-local federated data ecosystems (via blockchain) to scale up the potential of the co-operative action and outreach [72]. Citizens in communities will thus be using their own data, gathered in local repositories owned by them while contributing to data sharing if they would allow. This notion has been defined in the literature as 'data devolution' [71].

Actually, this is the case of Eva.coop, a Montreal-based data co-operative [73,74]: They provide an infrastructure for groups but without accessing local data about passengers. Some data are shared, however. Eva.coop is built on the EOSIO blockchain protocol as a way to show how the co-operative model could mark a new blockchain-based iteration of the sharing economy driven by decentralised system that respects user privacy and fits into local needs [75]. Local data matters, and Eva might have shed light on the way to follow. Local communities have more input, drivers are treated more fairly, riding members maintain their privacy, and are comforted by a locally supported app. Could this third generation of blockchain be a protocol from which to scale up a federated co-operative commonwealth based on structured data ecosystems by economic sectors (transport, healthcare, education, etc.) [76]?

Obviously, there are also obstacles. Communities will have to be educated about co-operative principles. Beyond that, such local data co-operatives may not be easily replicated because they are rooted in their contextual and territorial critical factors. Over time, governance within such co-operatives may also become a challenge: they could erode or be destroyed as some may people join, and others may have to be asked to leave. Therefore, this article recognises that data co-operatives cannot be seen as a one-stop shop that will fix all the ills of platform capitalism. This article suggests data co-operatives as an approach that is part of a toolbox that also includes efforts such as Solid [77], but also unions, neighbourhood associations, regulatory intervention, public ownership, and hybrid among these forms.

This article acknowledges, therefore, the limits of the framing of data co-operatives through data sovereignty. What does data sovereignty or ownership of a digital platform as a data co-operative mean when most communities and groups have so far relied on commercial upstream services? What does it mean when data co-operatives are using proprietary software and the cloud services of large tech companies? An alliance of cooperative data services offered from the margins might gradually overcome commercial upstream services by decentralising data governance models at the local level. At the very least, smart cities, not only communities in the Global North but also in the Global South, should be at the table when discussing legal instruments of data co-operatives. Co-operative scholars, historians, and leaders of organisations, especially from LGBTQI communities, indigenous people, minority languages' activists, and defenders of the right to decide in stateless nations, should be part of the conversations about legal templates and technological infrastructure for these data institutions [78,79]. An alliance of data services offered from the margins might help to diversify the digital economy gradually [61]. Understanding the thrill of pioneering legal or technical models for novel data management is very much required to set up data co-operatives. Nonetheless, proposals for data cooperatives should be co-developed with co-operative practitioners and connected to the long history and analysis of the various forms of co-operatives. In summary, data cooperatives will need to be anchored in local communities shaped by their specific cultural traits and features as a way to resist data colonialism [80-82].

There are probably few policy aspects worth considering for scaling up data cooperatives [83,84]: First, there is a clear need to reactivate civil societies for experimentation, paying special attention to city-regional unique features as clear sources of communitydriven sovereign data to foster the creation of locally based data co-operatives. Second, it is still likely necessary to provide enhanced training about the scope and functioning of co-operatives to enable fertilisation of data co-operatives. Third, procurement and 
public incentives are required to push ahead, enhance, and reinforce platform and data co-operatives beyond marginal experiments aligned with data donation and altruism.

Finally, initiatives around data co-operatives need to find their own strategic pathways amidst digital and social economy policy agendas in each regional context worldwide.

\section{People-Centred Smart Cities: Transitional Framework to Subvert Surveillance Capitalism and Sensory Power}

Against this backdrop, since 2018, UN-Habitat has been promoting the newly established smart city trend through its flagship programme entitled 'People-Centred Smart Cities' [13]. According to the UN-Habitat, 'digital technologies, depending on their use, can be a force that widens social gaps or reduces them'. Consequently, UN-Habitat aims to reduce digital inequality, building digital capacity, and ensuring that new technologies are a force for good. Insofar as UN-Habitat is supportive with the UN as the essential platform where all relevant actors, including governments, along with companies, technical experts, and civil society can come together to share policy expertise, and explore the possibility of a 'Global Commitment on Digital Trust and Security' (p. 1).

The 'People-Centred Smart Cities' programme flagged the necessity of bringing end users, citizens, and people back to the forefront of the analysis about smart cities. The recent awareness of the technopolitics of data in cities has led to a gradual, resilient, and joint urban reaction - pushed forward by the aftermath of the pandemic and exacerbated by the algorithmic crisis - which has put city governments at the forefront of safeguarding citizens' digital rights and communities' data sovereignty through the active procurement of data co-operatives, as was shown in the previous section. This awareness in cities has been supported by a policy reaction resulting in intensive discussions among cities and their urban stakeholders about ways to tackle the pandemic crisis by raising debates around the importance of data sovereignty. UN-Habitat is, therefore, currently amplifying an urban response that is gradually sparking an updated institutional, alternative, and experimental transitional version to the hegemonic smart city concept [16], as anticipated by the academic literature in the past $[85,86]$. UN-Habitat defines the 'People-Centred Smart Cities' approach as 'a way of re-thinking about the application of digital technologies by cities and communities that is grounded in human digital rights and principles of inclusion, hereby ensuring that no one and no place are left behind' [13] p. 1. According to this definition and further ongoing implementations on this reconceptualisation, this article elucidates that this new brand seems to foster an active role for end users, citizens, and people in communities as decision makers rather than mere data providers [26].

In a similar vein, the UN strategy on sustainable urban development highlights digital transformation and new technologies as one of four frontier issues that require a special, coordinated response. According to the New Urban Agenda, the adoption of a smart city approach should make use of opportunities from digitalisation, clean energy, and technologies. However, UN-Habitat acknowledges that in the absence of public oversight and accountability, data on citizens and communities are being extensively recorded, often by private companies, thereby raising concerns around privacy, surveillance, data sovereignty, and individual autonomy. In fact, the Office of the High Commissioner on Human Rights is working on understanding exactly how international human rights as digital rights can be applied in cyberspace and for smart cities.

In response to how digital literacy has been overlooked in many smart cities so far and closely following the contours of the 'People-Centred Smart City' debate, there has been a counter-reaction fuelled by the interplay of certain multi-stakeholders, highlighting the need for an ethically transparent data-driven society that reinforces the digital rights and data sovereignty of citizens through accountable data ethics $[87,88]$. This is the case of the Cities' Coalition for Digital Rights (CCDR), a city network established in 2018 by the local authorities of three main global smart cities: Barcelona, New York City, and Amsterdam [89]. Alongside this reaction, evidence-based decision making at local levels is needed to encourage the real and doable implementations of Sustainable Development Goals (SDGs) through local stakeholders. 
In response to the research question of this article regarding how we can describe in parallel the potential emerging alternative around data co-operatives through data sovereignty, given that both technopolitical notions are intertwined and are explicitly presented as key principles of the new 'People-Centred Smart Cities' approach (coined by UN-Habitat to subvert the negative side effects on social exclusion, digital, and data divide stemming from the existing and highly hegemonic surveillance capitalism and sensory power), UN-Habitat acknowledges the following flaws on smart city implementations so far: (i) lack of awareness of longstanding smartness in cities; (ii) overreliance on the optimisation narrative; (iii) lack of evidence and key performance indicators (KPIs); (iv) failure to engage residents in a meaningful manner; (v) privatisation of public infrastructure and services; (v) lack of transparent and structured data governance [16,90-93].

Hence, the 'People-Centred Smart City' approach was coined to renew the main principles of the smart city. The aim is to empower local governments to take a multistakeholder approach to digital transformations that realise sustainability, inclusivity, prosperity, and human digital rights for the benefit of all [94]. There are three key features of this approach for smart city local governments that resonate with the notions presented previously on data co-operatives and data sovereignty. The first feature is that technology should be evaluated for its ability to address the needs determined by the people it serves, and, by extension, data are considered assets in the hands of citizens. The second feature refers to the fact that citizens should be empowered to intervene and shape interventions in collaboration with the government or establish their own initiatives by using shareable data. The third feature addresses digital rights as the core that should lead to digital inclusion at all levels in smart cities $[95,96]$.

Stemming from the formulation of the 'People-Centred Smart City' approach, this new formulation elucidates the importance of autonomy and sovereignty about citizens' data and suggests $\mathrm{p} 2 \mathrm{p}$ mechanisms to manage, store, and even own data; this in itself may be a direct invitation (i) to consider data co-operatives as a feasible, doable, and desirable organisational forms and (ii) to empower communities and citizens through their digital right to claim their own data sovereignty. Therefore, in building 'People-Centred Smart Cities', local governments are entitled to protect digital rights, as well as tackle data and digital divide in communities from exclusive private sector data ownership or, in its most extreme form, surveillance capitalism and data extractivism and colonialism [29,81]. Data sovereignty claims to (i) enable equitable access to information and communication technology (ICT), (ii) open channels to harness residents' capacity and knowledge regardless of demographic, and (iii) support residents' development of smart city solutions on their own terms.

In conclusion, taking a 'People-Centred Smart City' approach means redefining the classic 'smart city' approach along these parameters by including explicitly the notions of data co-operatives and data sovereignty-namely, (i) orienting data co-operatives towards reflecting and serving the interests of residents, rather than focusing primarily on efficiency, top-down control, and the narrow interests of the technology industry; (ii) building inclusive, meaningful, and deliberate citizen participation, including extensive consultation, collaboration, and co-production; (iv) creating a citizenship framework underpinned by civil, social, political, symbolic, and digital rights based on data sovereignty for citizens and communities [97]; (v) protecting and leveraging digital public assets, including data, for the common good; and ultimately, (vi) focusing on projects and programming that make equity, democracy, and social justice key aspects of smart city initiatives [98].

\section{Conclusions}

The main contribution of this article is that of opening new research avenues by suggesting an alternative pathway to subvert surveillance capitalism and sensory power in smart cities. In doing so, this article illustrates an open debate in data governance and the data justice field related to current trends and challenges in smart cities [99]. Although there is an extremely preliminary development of this new pathway, this article sheds 
light on two intertwined notions that are paving the way towards the new approach about smart cities - data co-operatives and data sovereignty-coined recently by UN-Habitat as 'People-Centred Smart Cities'.

The novelty of this article lies in the fact that, so far, smart city literature has seldomly addressed technopolitical aspects, including $\mathrm{p} 2 \mathrm{p}$ data sharing and ownership organisational forms (e.g., data co-operatives) in relation to the current increased awareness of data sovereignty as possibly one of the most urgent challenges for post-COVID-19 smart cities. The research literature on co-operatives and sovereignty existed very much at the core of the debate about the technocratic mainstream and hegemonic approach of the smart city. 'People-Centred Smart Cities', as the main term popularised by UN-Habitat, may well provide a turning point in the understanding, meaning, and practices around the so-called smart city concept. Acknowledging the limitations related to the topics addressed, this article is, therefore, novel in terms of providing a sequence around previous research on data and platform co-operatives and technopolitical awareness of data in smart cities by advocating the need for serious consideration of data sovereignty, not only in its technopolitical dimension but also in its city-regional dimension.

Discussions on smart cities and recent literature on data governance and [100,101], more broadly, digital economy, society, and citizenship are already employing concepts, including data co-operatives $[11,17,52,53,66,78,83,84]$, data sovereignty $[12,18,19,46,49,50,65,68,78]$, data colonialism [21,80,82], and data devolution [14,20,22,69,71] (Figure 1). This article articulates this intertwined relationship by suggesting a more distinct interrelated conceptual angle that could be seen as an emerging trend in the field of smart cities [102].

In this vein, the new research line addressed in this article may evolve towards emerging horizons that stem from the current literature review and potential solutions that will probably lead to new research ideas around the unexplored city-regional and territorial dimensions so far. Despite the fact that data co-operatives are an emerging field of experimentation, there is still a necessary policy push worldwide to force them to leave the marginal or niche experiment zone. Data co-operatives are still not cemented in communityled structures and dynamics. Instead, data co-operatives may well exist because data altruism and donation are gradually taking over and opening up new possibilities for socially oriented data scientists and activists [103]. Regarding data sovereignty [104], it is equally true that data sovereignty-although interchangeably used sometimes as digital or technological sovereignty-is gaining momentum. Nonetheless, beyond the widespread assumption that these terms are broadly used, academic literature is scarce and inconclusive about the city-regional and territorial dimensions of sovereignty. As such, in several recent conferences such as 'Data Justice Lab 2021', data sovereignty seems to be reserved only for these 'global' issues by 'global' minorities; surprisingly assuming that linguistic minorities or stateless nations claims on their digital rights, particularly in Europe, are not 'global' enough as to be considered properly discussed in these academic discussions [61]. This article attempts to contribute to this necessary debate insofar as the European context is probably at stake at the moment without clear indications about how to federalise data through ecosystems, and, beyond the scope of this article, more importantly, how to federalise digitalisation through data ecosystems within and across nation-states $[79,105]$. This is the novelty to which this article contributes.

Thus, in the upcoming years, academic discussions and technopolitical implementations around data co-operatives and data sovereignty will evolve towards two main streams embedded in the city-regional (or territorial) dimension. Potentially, then, 'People-Centred Smart Cities' will inevitably need to consider and thus merge and gradually assemble both dimensions (Figure 1) [105], taking into account the following observations:

First, there is a need to establish data ecosystems at the city-regional level by ensuring a certain level of data devolution, which means bringing data back to citizens [14,71]. Consequently, data flows and sharing policy will be needed among different institutional layers through multi-level governance frameworks [20,69]. 
Second, in the post-COVID-19 era [10], data colonialism will disclose increasing differences among the Global South and the Global North [106,107]. Hence, the 'People Centred Smart Cities', as a newly branded concept coined by UN-Habitat, justifies this new approach for launching a new urban paradigm for both the Global North and the Global South, by which digitalisation and datafication require gradual decolonisation [108]. Indeed, it is noteworthy that as a result of the forthcoming new data regulation called Personal Information Protection Law (PIPL) in China, emulating the goals of the so-called GDPR and being effective from 1 November 2021, data sovereignty will conquer onwards an increasing amount of policy debates and discussions around the globe, sparking an insightful diversity of reactions [109].

This article has described in parallel the potential emerging alternative around data co-operatives through data sovereignty by presenting both. Consequently, the article offered a narrative to revisit and tackle the negative side effects on social exclusion, digital, and data divide characterised as clear consequences for communities and citizens of surveillance capitalism.

It goes without saying that the article attempted to address an ongoing debate on data and smart cities by providing existing practices and conceptualisations around data co-operatives, data sovereignty, and 'People-Centred Smart Cities'. As a way to open up the scope of the debate and enhance the plethora of options around it, it would be useful to clarify that this article offers an alternative view: It is far from the intention of this article to articulate the content as a dogmatic corpus. Instead, it offers ways to ensure inclusiveness by enriching the academic and policy discussions onwards.

Finally, it would be worthwhile if this article could be used as an inspiration for other conceptualisations and collection of cases worldwide regarding data co-operatives and data sovereignty by adding evidence to the prevailing nexus between smart cities and data.

Funding: This research was funded by the Economic and Social Research Council (ESRC), Grant Number ES/S012435/1 WISERD Civil Society: Changing Perspectives on Civic Stratification and Civil Repair.

Institutional Review Board Statement: Not applicable.

Informed Consent Statement: Not applicable.

Data Availability Statement: Not applicable.

Conflicts of Interest: The author declares no conflict of interest.

\section{References}

1. Prainsack, B. Oil crisis: The political economy of digital data. Conclusion of the special issue. Policy Stud. 2020, 41, 565-566. [CrossRef]

2. OECD. Data in the Digital Age; OECD: Paris, France, 2019.

3. European Commission. Proposal for a Regulation of the European Parliament and the Council; EC: Brussels, Belgium, 2021.

4. United Nations. Report of the Secretary General: Roadmap for Digital Cooperation; UN: Nairobi, Kenya, 2020.

5. Van Dijck, J. Datafication, dataism and dataveillance: Big data between scientific paradigm and ideology. Surveill. Soc. 2014, 12, 197-208. [CrossRef]

6. Van Dijck, J.; Hacker, K. The digital divide as a complex and dynamic phenomenon. Inf. Soc. 2003, 19, 315-326. [CrossRef]

7. Sadowski, J.; Viljoen, S.; Whittaker, M. Everyone should decide how their digital data are used-Not just tech companies. Nature 2021, 595, 169-171. [CrossRef]

8. Zuboff, S. The Age of Surveillance Capitalism: The Fight for a Human Future at the New Frontier of Power; Profile: London, UK, 2019.

9. Isin, E.; Ruppert, E. The birth of the sensory power: How a pandemic made it visible? Big Data Soc. 2020, 7, 1-15. [CrossRef]

10. Calzada, I. Smart City Citizenship; Elsevier Science Publishing Co Inc.: Cambridge, MA, USA, 2021. [CrossRef]

11. Scholz, T.; Calzada, I. Data Cooperatives for Pandemic Times; Public Seminar: New York, NY, USA, 2021.

12. Hummel, P.; Braun, M.; Tretter, M.; Dabrock, P. Data sovereignty: A review. Big Data Soc. 2021, 8. [CrossRef]

13. UN-Habitat. People-Centered Smart Cities; UN-Habitat: New York, NY, USA, 2018.

14. Calzada, I. The techno-politics of data and smart devolution in city-regions: Comparing Glasgow, Bristol, Barcelona, and Bilbao. Systems 2017, 5, 18. [CrossRef]

15. Calzada, I. Algorithmic Nations: Seeing like a city-regional and techno-political conceptual assemblage. Reg. Stud. Reg. Sci. 2018, 5, 267-289. [CrossRef] 
16. Calzada, I. People-Centered Smart Cities; UN-Habitat: New York, NY, USA, 2021; Forthcoming.

17. Calzada, I. Platform and data co-operatives amidst European pandemic citizenship. Sustainability 2020, 12, 8309. [CrossRef]

18. Vaile, D. The cloud and data sovereignty after Snowden. Aust. J. Telecommun. Digit. Econ. 2014, 2, 31-41. [CrossRef]

19. Woods, A.K. Litigating data sovereignty. Yale Law J. 2018, 128, 328-406.

20. Calzada, I.; Almirall, E. Data ecosystems for protecting European citizens' digital rights. Transform. Gov. People Process. Policy 2020, 14, 133-147. [CrossRef]

21. Couldry, N.; Mejias, U.A. Data colonialism: Rethinking Big Data's relation to the contemporary subject. Telev. New Media 2018, 20, 336-349. [CrossRef]

22. Barns, S. Re-engineering the city: Platform ecosystems and the capture of urban big data. Front. Sustain. Cities 2020, 2, 32. [CrossRef]

23. Kostka, G.; Antoine, L. Fostering model citizenship: Behavioral responses to China's emerging social credit systems. Policy Internet 2020, 12, 256-289. [CrossRef]

24. GDPR (General Data Protection Regulation). Available online: www.gdpr-info.eu (accessed on 8 August 2021).

25. CCPA (California Consumer Privacy Act). CCPA and GDPR Comparison Chart. Available online: https://iapp.org/resources/ article/ccpa-and-gdpr-comparison-chart/ (accessed on 8 August 2021).

26. Calzada, I. (Smart) Citizens from data providers to decision-makers? The case study of Barcelona. Sustainability 2018, 10, 3252. [CrossRef]

27. Scholz, T.; O’Brien, D.; Spicer, J. Can Cooperatives Build Worker Power? Give Platform Co-Ops a Seat at the Policy Table. Available online: www.publicseminar.org/2021/03/can-cooperatives-build-worker-power (accessed on 8 August 2021).

28. AWS. Available online: https://searchaws.techtarget.com/definition/Amazon-Web-Services (accessed on 8 August 2021).

29. Morozov, E. There Is a Leftwing Way to Challenge Big Tech for Our Data. Here It Is. Available online: https://www.theguardian. com/commentisfree/2018/aug/19/there-is-a-leftwing-way-to-challenge-big-data-here-it-is (accessed on 8 August 2021).

30. Sadowski, J. When data is capital: Datafication, accumulation, and extraction. Big Data Soc. 2019, 6, 1-12. [CrossRef]

31. Arcidiacono, D.; Pais, I. Re-embedding the economy within digitalized foundational sectors: The case of platform co-operativism. In The Foundational Economy; Barbera, F., Jones, I.R., Eds.; Policy Press: Bristol, UK, 2020; pp. 27-50.

32. Scholz, T. Platform Co-Operativism: Challenging the Corporate Sharing Economy; Rosa Luxemburg: New York, NY, USA, 2016.

33. Ada Lovelace Institute. Data Divide: Public Attitudes to Tackling Social and Health Inequalities in the COVID-19 Pandemic and Beyond. Available online: https:/ / www.adalovelaceinstitute.org/survey/data-divide/ (accessed on 8 August 2021).

34. McKenna, M. COVID-19 Vaccine Passports Are Coming. What Will That Mean? Available online: https://www.wired.com/ story/covid-19-vaccine-passports-are-coming-what-will-that-mean/ (accessed on 8 August 2021).

35. Burki, T. Equitable distribution of COVID-19 vaccines. Lancet Infect. Dis. 2021, 21, 33-34. [CrossRef]

36. Calzada, I. Pandemic citizenship: Will COVID-19 reinforce nation-states' borders and liquify citizens? Acad. Lett. 2021. [CrossRef]

37. Katz, I.T.; Weintraub, R.; Bekker, L.-G.; Brandt, A.M. From vaccine nationalism to vaccine equity: Finding a path forward. N. Engl. J. Med. 2021, 384, 1281-1283. [CrossRef]

38. Bieber, F. Global nationalism in times of the COVID-19 pandemic. Natl. Pap. 2020, 1-13. [CrossRef]

39. Ada Lovelace Institute. Citizens Biometric Council. Available online: https://www.adalovelaceinstitute.org/report/citizensbiometrics-council/ (accessed on 8 August 2021).

40. European Data Protection Board (EDPB-EDPS). Joint Opinion 03/2021 on the Proposal for a Regulation of the European Parliament and of the Council on European Data Governance Act; EDPB: Brussels, Belgium, 2021.

41. European Commission. A European Strategy for Data; European Commission: Brussels, Belgium, 2020.

42. European Commission. Proposal Regulation: European Data Governance Act. Available online: https://digital-strategy.ec. europa.eu/en/library/proposal-regulation-european-data-governance-data-governance-act (accessed on 8 August 2021).

43. EDPB. Available online: https://edpb.europa.eu/our-work-tools/our-documents/edpbedps-joint-opinion/edpb-edps-jointopinion-032021-proposal_en (accessed on 8 August 2021).

44. Carroll, S.R.; Rodriguez-Lonebear, D.; Martinez, D. Indigenous data governance: Strategies from United States Native Nations. Data Sci. J. 2019, 18, 1-31. [CrossRef]

45. Gilbert, J.; Lennox, C. Towards new development paradigms: The United Nations Declaration on the Rights of Indigenous Peoples as a tool to support self-determined development. Int. J. Hum. Rights 2019, 23, 104-124. [CrossRef]

46. Marley, T.L. Indigenous data sovereignty: University Institutional Review Board policies and guidelines and research with American Indian and Alaska native communities. Am. Behav. Sci. 2018, 63, 722-742. [CrossRef]

47. Mueller, M.L. Against sovereignty in cyberspace. Int. Stud. Rev. 2019, 22, 779-801. [CrossRef]

48. Rainie, S.C.; Schultz, J.L.; Briggs, E. Data as a strategic resource: Self-determination, governance, and the data challenge for indigenous nations in the United States. Int. Indig. Policy J. 2017, 8, 1-31. [CrossRef]

49. Kukutai, T.; Taylor, J. Indigenous Data Sovereignty; Australian National University: Canberra, Australia, 2016.

50. The First Nations Information Governance Centre. First Nations data sovereignty in Canada. Stat. J. IAOS 2019, 35, 47-69. [CrossRef] 
51. Craglia, M.; Scholten, H.; Micheli, M.; Hradec, J.; Calzada, I.; Luitjens, S.; Ponti, M.; Boter, J. Digitranscope: The Governance of Digitally-Transformed Society; EUR 30590 EN; Publications Office of the European Union: Luxembourg, 2021; ISBN 978-92-7630229-2. JRC 123362; Available online: https:/ / ec.europa.eu/jrc/en/publication/eur-scientific-and-technical-research-reports / digitranscope-governance-digitally-transformed-society (accessed on 8 August 2021). [CrossRef]

52. Pentland, A.; Hardjono, T. Data cooperatives. In Building the New Economy; MIT: Cambridge, MA, USA, 2021.

53. Hardjono, T.; Pentland, A. Data Cooperatives: Towards a Foundation for Decentralized Personal Data Management. arXiv. Available online: https:/ / ui.adsabs.harvard.edu/abs/2019arXiv190508819H (accessed on 8 August 2021).

54. Scholz, T.; Gelderblom, C. Building an Alternative to Amazon? Toward a Planetary-Scale, Pluralist Commonwealth for the Digital Economy. Public Seminar. Available online: https://publicseminar.org/essays/building-an-alternative-to-amazon/ (accessed on 8 August 2021).

55. Mozilla Foundation. What Is a Data Cooperative. Available online: https://foundation.mozilla.org/en/data-futures-lab/datafor-empowerment/shifting-power-through-data-governance/\#what-is-a-data-cooperative (accessed on 8 August 2021).

56. Mannan, M.; Schneider, N. Exit to Community: Strategies for Multi-Stakeholder Ownership in the Platform Economy; Georgetown Law Technology Review: Washington, DC, USA, 2020; Volume 4.

57. Digital Cooperative Research. You're Data. You're Control. You're Profit. Available online: https://medium.com/digitalcooperative-research/youre-data-you-re-control-you-re-profit-5a181948011 (accessed on 8 August 2021).

58. Ada Lovelace Institute. Exploring Legal Mechanisms for Data Stewardship; Ada Lovelace Institute: London, UK, 2021.

59. Loi, M.; Dehaye, P.-O.; Hafen, E. Towards Rawlsian 'property-owning-democracy' through personal data platform cooperatives. Crit. Rev. Int. Soc. Political Philos. 2020, 1-19. [CrossRef]

60. Mathiesen, K. Human Rights for the Digital Age. J. Mass Media Ethics 2014, 29, 2-18. [CrossRef]

61. Milan, S.; Treré, E.; Maseiro, S. COVID-19 from the Margin: Pandemic Invisibilities, Policies, and Resistance in the Datafied Society; Institute of Network Cultures: Amsterdam, The Netherlands, 2021.

62. Csernatoni, R. New states of emergency: Normalizing techno-surveillance in the time of COVID-19. Glob. Aff. 2020, 6, 301-310. [CrossRef]

63. Calzada, I. Pandemic Citizenship amidst Stateless Algorithmic Nations: Digital Rights and Technological Sovereignty at Stake; Coppieters Foundation/Post-Covid Europe Series/4: Brussels, Available online: https://ideasforeurope.eu/activity/paper/ pandemic-citizenship-amidst-stateless-algorithmic-nations-post-covid-europe-4/ and https://ideasforeurope.eu/activity/ event/conversations-on-digital-rights/; (accessed on 26 August 2021). [CrossRef]

64. Platform Cooperativism Consortium. Available online: https:// platform.coop/blog/platform-co-ops-now-2nd-edition/ (accessed on 8 August 2021).

65. De Filippi, P.; McCarthy, S. Cloud computing: Centralisation and data sovereignty. Eur. J. Law Technol. $2012,3,1-18$.

66. Naeem, I.; Nurul, H.A.; Vaska, M.; Goopy, S.; Kassan, A.; Aghajafari, F.; Kazi, A.; Rashid, R.; Ferrer, I.; O’Beirne, M.; et al. Community-based health data cooperatives towards improving the immigrant community health: A scoping review to inform policy and practice. Int. J. Popul. Data Sci. 2021, 5, 1158. [CrossRef]

67. Couture, S.; Toupin, S. What does the notion of 'sovereignty' mean when referring to the digital? New Media Soc. 2019, 21, 2305-2322. [CrossRef]

68. Esposito, C.; Castiglione, A.; Frattini, F. On data sovereignty in cloud-based computation offloading for smart cities applications. IEEE Internet Things J. 2019, 6, 4251-4535. [CrossRef]

69. Kigsing, M. The Political Economy of Digital Ecosystems: Scenario Planning for Alternative Futures; Routledge: Oxon, UK, 2022.

70. Loukissas, Y.A. All Data Are Local: Thinking Critically in a Data-Driven Society; MIT Press: Cambridge, MA, USA, 2019.

71. Calzada, I. Chapter 6-Devolving Smart City Citizenship: Smart City-Regions, Data Devolution, and Technological Sovereignty. In Smart City Citizenship; Igor, C., Ed.; Elsevier Science Publishing Co Inc.: Cambridge, MA, USA, 2021; pp. 219-234. ISBN 9780128153000. [CrossRef]

72. De Filippi, P.; Mannan, M.; Reijers, W. Blockchain as a confidence machines: The problem of trust \& challenges of governance. Technol. Soc. 2020, 62, 1-14. [CrossRef]

73. Eva.coop. Eva Coop Innovates Ride-Sharing with Blockchain. Available online: https://www.voice.com/post/@machnbirdsparo/ eva-coop-innovates-ridesharing-with-blockchain-1611898466-1746146899 (accessed on 8 August 2021).

74. Eva.coop. Available online: https:/ / eva.coop/files/LP.pdf (accessed on 8 August 2021).

75. Robey, A. How Community Token Can Power Cooperatives. Available online: https://forefront.news/blog/how-communitytokens-can-power-cooperatives (accessed on 8 August 2021).

76. Wachira, A. Co-Operatives and Blockchain: A Perfect Match? Available online: https://businessblockchainhq.com/businessblockchain-news/co-operatives-and-blockchain-a-perfect-match/ (accessed on 8 August 2021).

77. Solid. Available online: https://solid.mit.edu/ (accessed on 8 August 2021).

78. Calzada, I. Postpandemic technopolitical democracy: Algorithmic nations, data sovereignty, digital rights, and data co-operatives. In Democratic Deepening: Emerging Forms of Scales for Developing Democracy and Citizen Participation; Zabalo, J., Filibi, I., Escacedo, L., Eds.; Springer: New York, NY, USA, 2021; Forthcoming.

79. Calzada, I. Digitalisation: Potentially Federalising. In Proceedings of the Summer School on the Future of the European Union: A Vision from the Basque Country, Contributions to the Conference, EuroBasque and the University of the Basque Country, Donostia-San Sebastián, Spain, 8-9 July 2021. [CrossRef] 
80. Mouton, M.; Ryan, B. (Digital) neo-colonialism in the smart city. Reg. Stud. 2021, 1-12. [CrossRef]

81. Couldry, N.; Mejias, U.A. The Costs of Connection: How Data is Colonizing Human Life and Appropriating It for Capitalism; Stanford University Press: Stanford, CA, USA, 2020.

82. Couldry, N.; Mejias, U.A. Making data colonialism liveable: How might data's social order be regulated? Internet Policy Rev. 2019, 8. [CrossRef]

83. Hafen, E. Personal data cooperatives-A new data governance framework for data donations and precision health. In The Ethics of Medical Data Donation; Krutzinna, J., Floridi, L., Eds.; Springer: Cham, Switzerland, 2019; pp. 141-149.

84. Blasimme, A.; Vayena, E.; Ernst, H. Democratizing health research through data cooperatives. Philos. Technol. 2018, 31, 473-479. [CrossRef]

85. Hollands, R.G. Will the real smart city please stand up? City 2008, 12, 303-320. [CrossRef]

86. Hollands, R.G. Critical interventions into the corporate smart city. Camb. J. Reg. Econ. Soc. 2014, 8, 61-77. [CrossRef]

87. Barassi, V. Digital citizens? Data traces and family life. Contemp. Soc. Sci. 2017, 12, 84-95. [CrossRef]

88. Ada Lovelace Institute, AI Now Institute, and Open Government. Algorithmic Accountability for the Public Sector: Learning from the First Wave of Policy Implementation. Available online: https:/ /www.opengovpartnership.org/documents/algorithmicaccountability-public-sector/ (accessed on 24 August 2021).

89. Cities' Coalition for Digital Rights. Available online: www.citiesfordigitalrights.org (accessed on 8 August 2021).

90. Park, S.; Humphry, J. Exclusion by design: Intersections of social, digital, and data exclusion. Inf. Commun. Soc. 2019, 22, 934-953. [CrossRef]

91. Galic, M.; Schuilenburg, M. Reclaiming the Smart City: Toward a New Right to the City. In Handbook of Smart Cities; Galic, M., Schuilenburg, M., Eds.; Springer Nature: Cham, Switzerland, 2020.

92. Komninos, N.; Kakderi, C.; Mora, L.; Panori, A.; Sefertzi, E. Towards high impact smart cities: A universal architecture based on connected intelligence spaces. J. Knowl. Econ. 2021, 1-29. [CrossRef]

93. Kitchin, R. Afterword: Decentering the smart city. In Equality in the City: Imaginaries of the Smart Future; Flynn, S., Ed.; Intellect: Bristol, UK, 2021.

94. Calzada, I. Democratising smart cities? Penta helix multistakeholder social innovation framework. Smart Cities 2020, 3, 57. [CrossRef]

95. Breuer, J.; Pierson, J. The right to the city and data protection for developing citizen-centric digital cities. Inf. Commun. Soc. 2021, 24, 797-812. [CrossRef]

96. Pierson, J. Digital platforms as entangled infrastructures: Addressing public values and trust in messaging apps. Eur. J. Commun. 2021, 36, 349-361. [CrossRef]

97. Calzada, I. Chapter 7-Protecting smart city citizenship: Citizens' digital rights and AI-driven algorithmic disruption. In Smart City Citizenship; Igor, C., Ed.; Elsevier Science Publishing Co Inc.: Cambridge, MA, USA, 2021; pp. 219-234. ISBN 9780128153000. [CrossRef]

98. Lytras, M.; Visvizi, A.; Kwok, T.C. Big data research for social sciences and social impact. Sustainability 2020, 12, 180. [CrossRef]

99. Calzada, I.; Cobo, C. Unplugging: Deconstructing the Smart City. J. Urban Technol. 2015, 22, 23-43. [CrossRef]

100. Calzada, I. Replicating smart cities: The city-to-city learning programme in the Replicate EC-H2020-SCC project. Smart Cities 2020, 3, 978-1003. [CrossRef]

101. Micheli, M.; Ponti, M.; Craglia, M.; Suman, A.B. Emerging models of data governance in the age of datafication. Big Data Soc. 2020, 7, 1-15. [CrossRef]

102. Löfgren, K.; Webster, C.W.R. The value of Big Data in government: The case of 'smart cities'. Big Data Soc. 2020, 7. [CrossRef]

103. Graham, M. Regulate, replicate, and resist-The conjunctural geographies of platform urbanism. Urban Geogr. 2020, 41, 453-457. [CrossRef]

104. Floridi, L. The flight for digital sovereignty: What it is, and why it matters, especially for the EU. Philos. Technol. 2020, 33, 369-378. [CrossRef]

105. Calzada, I. Benchmarking future city-regions beyond nation-states. Reg. Stud. Reg. Sci. 2015, 2, 350-361. [CrossRef]

106. Parnell, S.; Robinson, J. (Re)theorizing cities from the Global South: Looking beyond neoliberalism. Urban Geogr. 2012, 33, 593-617. [CrossRef]

107. Datta, A. New urban utopias of postcolonial India: Entrepreneurial urbanization in Dholera smart city, Gujarat. Dialogues Hum. Geogr. 2015, 5, 3-22. [CrossRef]

108. UNITAC. United Nations Innovation Technology Accelerator for Cities (UNITAC) Hamburg. Available online: https://unhabitat. org/ un-habitat-and-the-federal-republic-of-germany-establish-a-united-nations- $\%$ E2\%80\%98innovation-technology (accessed on 27 August 2021).

109. Gamvros, A.; Wang, L. PIPL: A Game Changer for Companies in CHINA. Available online: https:/ /www.dataprotectionreport. com/2021/08/pipl-a-game-changer-for-companies-in-china/ (accessed on 29 August 2021). 